\title{
The feasibility of airways hyperresponsiveness as an inclusion criterion for studies on childhood asthma
}

\author{
A.W.A. Kamps*, M.J. Visser" ${ }^{\#}$, T.W. de Vries ${ }^{\star}$, W.M.C. van Aalderen ${ }^{+}$, D.S. Postma ${ }^{\#}$, P.L.P. Brand*
}

The feasibility of airways hyperresponsiveness as an inclusion criterion for studies on childhood asthma. A.W.A. Kamps, M.J. Visser, T.W.de Vries, W.M.C.van Aalderen, D.S. Postma, P.L.P. Brand. (C) ERS Journals Ltd 2001.

ABSTRACT: The feasibility of moderately severe airway hyperresponsiveness (AH) was examined as an inclusion criterion for clinical trials in asthmatic children.

During the baseline period of a long-term clinical trial in asthmatic children, maintenance therapy with fluticasone $\left(200 \mu \mathrm{g} \cdot \mathrm{day}^{-1}\right)$ was stopped for a maximum of 8 weeks and methacholine challenges were performed at 2-week intervals or earlier if the patients' condition deteriorated. Patients were eligible to continue the study if the provocative dose of methacholine causing a $20 \%$ fall in forced expired volume in one second (FEV1) (PD20) was $<80 \mu \mathrm{g}$.

Fifty-one per cent of the children did not develop a PD20 $<80 \mu \mathrm{g}$ after withdrawal of fluticasone. Patients with or without a PD20 $<80 \mu \mathrm{g}$ did not differ in duration of asthma, duration of treatment, or peak flow variation. Patients with a PD20 $<80 \mu \mathrm{g}$ had higher levels of total and specific immunoglobulin-E, and lower levels of FEV1 and mean maximal expiratory flow than patients with a PD20 $\geqslant 80 \mu \mathrm{g}$. Forty-four per cent of the patients with a PD20 $\geqslant 80 \mu \mathrm{g}$ did not have any symptoms during the wash-out period and $39 \%$ of these patients remained free from symptoms during one year followup.

The results of this study suggest that recruiting asthmatic children for clinical trials may be difficult if airways hyperresponsiveness is used as the sole inclusion criterion. Eur Respir J 2001; 17: 887-891.
*Dept of Pediatrics, Isala Klinieken/ Weezenlanden Hospital, 8000 GM Zwolle, " Dept of Pulmonology, University Hospital, Groningen, Dept of Pediatrics, Medical Center Leeuwarden and ${ }^{+}$Dept of Pediatrics, Emma Children's Hospital, Amsterdam, the Netherlands.

Correspondence: P.L.P. Brand, Dept of Pediatrics, Isala Klinieken/Weezenlanden Hospital, PO Box 10500, 8000 GM Zwolle, the Netherlands

Fax: 31384242734

Keywords: Airway hyperresponsiveness childhood asthma

inclusion criterion

Received: July 242000

Accepted after revision January 32001

This study was sponsored by GlaxoWellcome (the Netherlands)
Current guidelines for the treatment of childhood asthma emphasize the use of inhaled corticosteroids (ICS) as first-line treatment [1, 2]. Airways hyperresponsiveness $(\mathrm{AH})$ continues to improve throughout the first 2 yrs after institution of ICS therapy [3-5]. Therefore, if differences between various types or dosages of ICS are to be examined in clinical trials, the extent to which $\mathrm{AH}$ improves is a useful end-point. This is why a certain degree of $\mathrm{AH}$ has been frequently used as an inclusion criterion for clinical trials in childhood asthma over the past years $[3,6,7]$.

Children with asthma who are currently approached for participation in clinical trials generally use ICS therapy already, sometimes even for many years. Most of these patients will have a normal or near-normal level of lung function [8]. As a result, a certain degree of airways obstruction may no longer be a valid inclusion criterion for clinical trials in childhood asthma [9]. Although not formally investigated so far, this might be the case for $\mathrm{AH}$ as well.

During the patient recruitment period of an ongoing long-term study comparing different dosing schedules of ICS, the feasibility of moderately severe AH was examined as an inclusion criterion for clinical trials in school-aged asthmatic children.

\section{Patients and methods}

For this report, baseline data from an ongoing longterm study on ICS in childhood asthma were used. In this study, two dosage schedules of ICS are compared over a period of 2 yrs, using the improvement in $\mathrm{AH}$ as one of the main end-points. In order to be able to detect differences between different dosage schedules of ICS during the study period (rather than comparing ICS to placebo), moderate-to-severe $\mathrm{AH}$ (defined as a provocative dose of methacholine causing a $20 \%$ fall in forced expiratory volume in one second (FEV1) (PD20) of $<80 \mu \mathrm{g}$ ) after withdrawal of ICS was an inclusion criterion.

Children, 6-10 yrs of age, with a clinical diagnosis of asthma, were recruited from the outpatient clinics of the three participating hospitals. None of these patients had, due to their age at presentation, undergone methacholine challenges before entering the study. After obtaining written informed parental consent, patients were switched from their usual maintenance therapy to fluticasone propionate $100 \mu \mathrm{g}$ b.i.d. via dry powder inhaler (Diskhaler $\AA$, GlaxoWellcome) for 6 weeks (run-in period). No other maintenance treatment for asthma was allowed. The main objective of 
this run-in period was to familiarize all patients with the inhaler device to be used during the whole study period. At the end of the run-in period, a baseline methacholine provocation test was performed. Subsequently, fluticasone propionate was stopped for a maximal period of 8 weeks (wash-out), and patients were only allowed to use inhaled short acting bronchodilator (salbutamol) for relief of symptoms. Methacholine provocation tests were performed at 2-week intervals or earlier if symptoms of asthma increased. The methacholine tests were performed with a dosimeter method as described elsewhere [10]. The usual cut-off level between "normal" airways responsiveness and AH using this method is a PD20 of $150 \mu \mathrm{g}$ [11].

At each follow-up visit patients were asked if they had experienced symptoms of cough, wheeze, or dyspnoea. During the wash-out period, patients kept a diary in which symptoms and peak expiratory flow (PEF) were recorded. The highest of three PEF manoeuvres was recorded in the morning and evening. PEF variation was calculated as the lowest PEF level during the first 2 weeks of the wash-out period as a percentage of the highest PEF level recorded in this period (low $\%$ high) [4].

The patients entered the randomized part of the study as soon as they developed AH (PD20 <80 $\mu \mathrm{g})$. If PD20 was $\geqslant 80 \mu \mathrm{g}$ after a wash-out period of 8 weeks, patients were withdrawn from the study and treated according to the judgment of their paediatric pulmonologist. Follow-up data from these patients were collected from their medical records.

In all patients, blood was drawn for determination of total and allergen-specific immunoglobulin-E (IgE) concentrations. Allergen-specific IgE concentrations (to house dust mite, grass and tree pollen, and cat and dog dander) were determined by a radio-allergosorbent test (RAST) (Pharmacia, Uppsala, Sweden). A RAST was considered positive when the result read class 2 or higher. From their medical records, the mean daily dose of ICS (cumulative dose divided by time of treatment in days) was determined.

Differences between groups were analysed using the
Mann-Whitney U-test and Chi-squared test as appropriate. To examine whether age was associated with AH, logistic regression analysis was carried out. Seasonal variation in the degree of $\mathrm{AH}$ was tested by nonparametric analysis of variance (ANOVA).

The study was approved by the ethics review boards of all three participating hospitals.

\section{Results}

\section{Patient characteristics}

Ninety-five children completed the run-in and washout period of the study. All patients had been treated with ICS for asthma before entering the study. At the end of the 6-week run-in period, during which all patients used $200 \mu \mathrm{g}$ fluticasone daily, $8(8.4 \%)$ had a PD20 < $80 \mu \mathrm{g}$, and $14(14.7 \%)$ had a PD20 < $150 \mu \mathrm{g}$. There were no data available on previous tests of airways hyperresponsiveness before the patients were using ICS. Forty-seven (49\%) of the 95 patients who completed the run-in and wash-out period developed AH (PD20<80 $\mu \mathrm{g})$, and $48(51 \%)$ did not. The latter group had significantly higher FEV1 \% pred and mean maximal expiratory flow (MEF50) \% pred values, and lower IgE levels as well as a lower prevalence of RAST positivity. Demographic and clinical characteristics of the patients are presented in table 1 . Forty-three $(90 \%)$ of the 48 patients with a PD20 $\geqslant 80 \mu \mathrm{g}$, had a PD20 $>150 \mu \mathrm{g}$. Age was not associated with AH (odds ratio $0.9 ; 95 \%$ confidence interval $0.7-1.3$ ).

\section{Symptoms during the wash-out period and after withdrawal of inhaled corticosteroids}

During the 8-week wash-out period, 21 (44\%) of the patients without $\mathrm{AH}$ had no symptoms of cough, wheeze or dyspnoea on exertion. These children were considered to be in clinical remission of their asthma. The other 27 patients $(56 \%)$ reported asthmatic symptoms, including cough in 16 and wheeze in 10 (fig. 1). Characteristics of the patients with a PD20

Table 1.-Demographic and clinical characteristics of the patients with and without airways hyperresponsiveness $(\mathrm{AH})$

\begin{tabular}{lccc}
\hline & AH PD20<80 $\mu \mathrm{g}$ & No AH PD20 $\geqslant 80 \mu \mathrm{g}$ & $\mathrm{p}$-value \\
\hline Subjects $\mathrm{A}$ & 47 & 48 & \\
Age yrs & $8.1 \pm 1.2$ & $8.2 \pm 1.2$ & 0.54 \\
Male children \% & 52 & 57 & 0.74 \\
Duration of asthma yrs & $5.1 \pm 2.0$ & $5.0 \pm 2.1$ & 0.74 \\
Duration of ICS yrs & $2.7 \pm 1.5$ & $2.5 \pm 1.7$ & 0.48 \\
Mean daily dose of ICS received prior to entering study $\mu \mathrm{g}$ & $361 \pm 97$ & $328 \pm 104$ & 0.12 \\
FEV1 at end of washout period \% pred & $92.1 \pm 16.8$ & $98.3 \pm 18.0$ & 0.03 \\
MEF50 at end of washout period \% pred & $63.5 \pm 23.3$ & $72.1 \pm 22.0$ & 0.03 \\
PEF Low\%High & $72.1 \pm 12.3$ & $74.3 \pm 13.5$ & 0.33 \\
IgE kU.1 & $457(29-3966)$ & $132(2-4500)$ & 0.001 \\
RAST positive \% & 80.0 & 54.0 & 0.01 \\
PD20 $\mu \mathrm{g}$ & $31.8(3.5-76)$ & $665.3(95-1565)$ & $<0.0001$ \\
\hline
\end{tabular}

Data are presented as mean $\pm \mathrm{SD}$, or as geometric mean (range). ${ }^{*}$ : Mann Whitney U-test or Chi-squared test; ${ }^{\top}$ : Peak expiratory flow (PEF) variation calculated as the lowest PEF level as a percentage of the highest PEF level recorded during the first two weeks of the wash-out period. ICS: inhaled corticosteroids; FEV1: forced expiratory volume in one second; MEF50: mean maximal expiratory flow; IgE: immunoglobulin-E; RAST: radioallergosorbent test; PD20: provocative dose of methacholine causing a $20 \%$ fall in FEV 1 . 


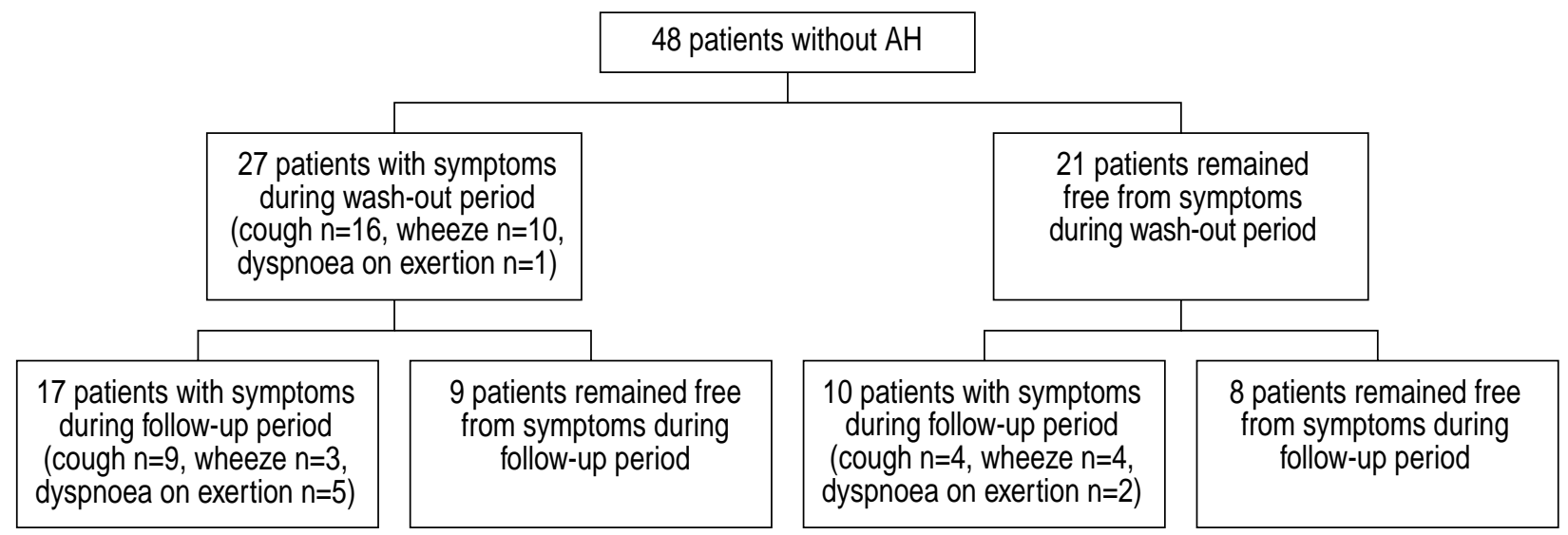

Fig. 1. - Symptoms of asthma in patients without airways hyperresponsiveness (AH) both during the wash-out period and the follow-up period. Four patients were lost to follow-up.

$\geqslant 80 \mu \mathrm{g}$ with and without any symptoms during the wash-out period are presented in table 2 . All patients with a PD20 $<80 \mu \mathrm{g}$ reported symptoms of asthma during the wash-out period.

After withdrawal from the trial, patients without $\mathrm{AH}$ were followed-up for a median period of 13 months (range 2-32 months). Four patients were lost to follow-up because they moved to another area or missed follow-up appointments. Of the remaining 44 patients, $17(39 \%)$ remained free from symptoms. The remainder had mild asthmatic symptoms (cough in 13, wheeze in 7, dyspnoea on exertion in 7, fig. 1). More than half of these patients were atopic with at least one positive RAST (table 1).

\section{Seasonal variation in airway hyperresponsiveness}

There was a seasonal variation in the degree of $\mathrm{AH}$ in the patients. AH was significantly lower in the spring (April, May, and June) than in the winter, summer, and autumn (nonparametric ANOVA, p=0.01) (fig. 2).

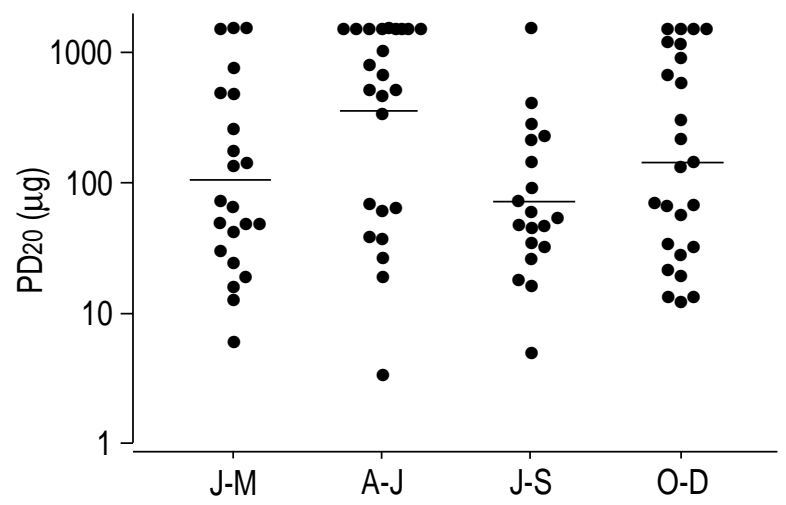

Fig. 2. - Seasonal variation in the degree of airway hyperresponsiveness. Horizontal lines represent geometric mean values of provocative dose of methacholine causing a $20 \%$ fall in forced expiratory volume in one second (PD20) for each season. The $\mathrm{PD} 20$ is significantly higher during the spring months (nonparametric analysis of variance, $\mathrm{p}=0.01)$. ( J-M January to March, A-J April to June, J-S July to September, O-D October to December).

Table 2. - Demographic and clinical characteristics of the patients with provocative dose of methacholine causing a $20 \%$ fall in forced expiratory volume in one second $\left(\mathrm{FEV}_{1}\right)(\mathrm{PD} 20) \geqslant 80 \mu \mathrm{g}$ with and without symptoms during the wash-out period

PD $20<80 \mu \mathrm{g}$ With symptoms $\quad$ PD20 $\geqslant 80 \mu \mathrm{g}$ Without symptoms p-value $^{\#}$

Subjects $n$

Age yrs

Male children $\%$

Duration of asthma yrs

Duration of ICS yrs

Mean daily dose of ICS prior to entering study $\mu \mathrm{g}$

FEV1 measured at end of washout \% pred

MEF50 measured at end of washout \% pred PEF Low\%High

$\operatorname{IgE~} \mathrm{kU} \cdot \mathrm{L}^{-1}$

RAST positive $\%$

PD20 $\mu \mathrm{g}$
27

$8.1 \pm 1.2$

75

$4.7 \pm 2.1$

$2.5 \pm 1.6$

$303 \pm 84$

$96.6 \pm 21.0$

$69.0 \pm 25.1$

$69.8 \pm 15.4$

$195(18-1538)$

60.0

$562.3(136-1565)$
21

$8.3 \pm 1.1$

42

$5.5 \pm 2.0$

$2.7 \pm 1.9$

0.01

0.26

$340 \pm 81$

$101.6+12.8$

$77.5 \pm 16.1$

$80.5 \pm 7.8$

$87(2-4500)$

54.0

$912(182-1565)$

0.14

0.73

0.30

0.02

0.27

0.32

0.03

Data are presented as mean $\pm \mathrm{SD}$, or as geometric mean (range). ${ }^{\#}$ : Mann Whitney U- or Chi-squared test; ${ }^{\circ}$ : Peak expiratory flow (PEF) variation calculated as the lowest PEF level as a percentage of the highest PEF level recorded during the first two weeks of the wash-out period. ICS: inhaled corticosteroids; MEF50: mean maximal expiratory flow; IgE: immunoglobulin-E; RAST: radioallergosorbent test; PD20: provocative dose of methacholine causing a 20\% fall in FEV1. 


\section{Discussion}

Although many children with mild asthma in population studies may not show $\mathrm{AH},[12,13]$ previous hospital-based studies of childhood asthma suggested that most, if not all, school-aged asthmatic children had AH [3, 6, 7, 14]. The results of the present study show that at present many school-aged children in the Netherlands who have been treated with ICS because of asthma for prolonged periods of time, do not have $\mathrm{AH}$ after withdrawal of ICS (whether defined as a PD20 $<80$ or $<150 \mu \mathrm{g}$ [6]). Other researchers in Western Europe share the same experience (A.A.P.H. VaessenVerberne, Amphia Medical Centre, Breda, the Netherlands and S. Pedersen, Kolding Hospital, Kolding, Denmark, personal communication).

A drawback of the present study is the lack of data on presence or absence of $\mathrm{AH}$ prior to entering the trial. This, however, reflects current practice in preschool children. Methacholine challenges using FEV1 to monitor responses are not feasible in this age group. Therefore, although it is possible that some nonhyperresponsiveness children in the present study were never hyperresponsive, testing this hypothesis is unlikely to be successful. Nevertheless, they all had persistent respiratory symptoms initially, severe enough to be referred to a paediatric pulmonologist.

Most of the children in this study had been diagnosed with and treated for asthma from preschool age onwards. It is now clear that wheezing during preschool years is a heterogeneous condition that may be transient in many children [15]. The children who did not develop $\mathrm{AH}$ and remained asymptomatic after withdrawal of ICS in this study could thus be viewed as transient wheezers without AH $[16,17]$. The present findings of a higher prevalence of atopic sensitization in children with $\mathrm{AH}$ than in those without $\mathrm{AH}$ is in agreement with earlier findings in such transient wheezers [15]. Furthermore, the larger degree of PEF variation in symptomatic than in asymptomatic children without $\mathrm{AH}$, also fits with this observation [16]. In contrast, the fact that almost half of the patients developed $\mathrm{AH}$ while most of them did not demonstrate $\mathrm{AH}$ during treatment with ICS, favours a diagnosis of asthma in these patients. In prospective studies, the only feature predicting which wheezers will cease wheezing is the lack of atopy $[15,16,18]$. The proportion of atopic patients in the present study's nonhyperresponsive patients $(54 \%$, table 1$)$ is higher than that in studies from England $(36 \%)$ [18] and USA $(32 \%)$ [15]. This suggests that in the present study group, there were more atopic patients with transient wheeze than in previous studies. A striking difference between these previous studies and the present one is the more widespread use of ICS from an early age onwards in this study group. Because this study group was not characterized extensively and prospectively at a young age, it is impossible to come to a definite conclusion about whether the nonhyperresponsive patients in this study were transient wheezers or truly asthmatics in long-lasting clinical remission.

A recent study from Canada showed that almost all asthmatic children who had been treated in a hospital clinic from the age of 3-4 yrs onwards, demonstrated AH when re-examined 6 yrs later, whether they were symptomatic or not [14]. In the latter study, only $40 \%$ of the symptomatic patients were using regular maintenance treatment with ICS, whereas all asthmatic children in the present study had used ICS for $0.2-7.6$ yrs. Tentatively, the lack of $\mathrm{AH}$ in the present study in many children after withdrawal of ICS may reflect a long-lasting remission of childhood asthma caused by ICS therapy when instituted at an early age and continued for a prolonged period of time. It has been shown that withdrawal of ICS in older asthmatic children and adults results in rapid deterioration of symptoms and AH [19, 20]. It is possible that ICS therapy in young children could truly stop asthmatic airways inflammation before it becomes persistent and irreversible [21]. An interesting observation in this respect is that both FEV1 and MEF50, reflecting large and small airways calibre respectively, were significantly higher in children without $\mathrm{AH}$ than in children with AH. This suggests a beneficial effect of prolonged ICS therapy on both large and small airways function in young children with asthma. This is in agreement with the observation of chronic persistent asthmatic inflammation in both large and small airways in adults [22].

There was a lower level of $\mathrm{AH}$ in the children tested during the spring months (fig. 2). This could be due to low exposure to house dust mite [23], the predominant inhalant allergen in the Netherlands, or a lower viral infection load. It is unlikely, however, that this phenomenon is responsible for the lack of $\mathrm{AH}$ observed in approximately one-half of the asthmatic children in the present study, because only 26 children were tested during the spring months (fig. 2), and eight of them showed AH.

Even though many of the asthmatic children failed to show AH (as traditionally defined), the PD20 level after withdrawal of ICS was significantly lower in the group of children who redeveloped asthmatic symptoms during further follow-up than in the children who remained asymptomatic (table 2). This suggests that because ICS are used broadly in the majority of children with asthma, cut-off levels for AH may need to be redefined.

There are several ways to assess $\mathrm{AH}$ in children, and it has been argued that "indirect" AH (as assessed by, for example, exercise, adenosine, or hypertonic saline) would be more closely related to current asthma than "direct challenge" (methacholine) that was used in the present study [24, 25]. Further studies are needed to determine whether the present findings are reproduced when using an indirect challenge test.

In summary, this study shows that airways responsiveness may be markedly reduced (to levels usually encountered in nonasthmatics) after withdrawal of long-term treatment with inhaled corticosteroids in 6-10 yr old children with asthma. In addition, recruiting asthmatic children for clinical trials may be difficult if airways hyperresponsiveness is used as the sole inclusion criterion. 


\section{References}

1. The British Thoracic Society, The National Asthma Campaign, The Royal College of Physicians of London in association with the general practitioner in asthma group, the British Association of accident and emergency medicine, the British paediatric respiratory society, the Royal College of paediatrics and child health. The British guidelines on asthma management: 1995 review and position statement. Thorax 1997; 52: Suppl. 1, S2-S21.

2. National Heart Lung and Blood Institute, National Institutes of Health. International consensus report on diagnosis and treatment of asthma (NHLBI Publication No. 92-3091, March 1992). Eur Respir J 1992; 5: $601-641$.

3. van Essen-Zandvliet EEM, Hughes MD, Waalkens HJ, Duiverman EJ, Pocock SJ, Kerrebijn KF. Effects of 22 months of treatment with an inhaled corticosteroid and/or B2 agonists on lung function, airway responsiveness, and symptoms in children with asthma. Am Rev Respir Dis 1992; 146: 547-554.

4. Brand PLP, Duiverman EJ, Waalkens HJ, van EssenZandvliet EEM, Kerrebijn KF, and the Dutch CNSLD Study Group. Peak flow variation in childhood asthma: correlation with symptoms, airways obstruction, and hyperresponsiveness during longterm treatment with inhaled corticosteroids. Thorax 1999; 54: $103-107$.

5. Hofstra WB, Neijens HJ, Duiverman EJ, et al. Dose response over time to inhaled fluticasone propionate treatment of exercise- and methacholine-induced bronchoconstriction in children with asthma. Pediatr Pulmonol 2000; 29: 415-423.

6. Verberne AAPH, Frost C, Roorda RJ, van der Laag $\mathrm{H}$, Kerrebijn KF. One year treatment with salmeterol compared with beclomethasone in children with asthma. The Dutch Paediatric Asthma Study Group. Am J Respir Crit Care Med 1997; 156: 688-695.

7. Verberne AAPH, Frost C, Duiverman EJ, Grol MH, Kerrebijn KF. Addition of salmeterol versus doubling the dose of beclomethasone in children with asthma. The Dutch Paediatric Asthma Study Group. Am J Resp Crit Care Med 1998; 158: 213-219.

8. Korppi M, Remes K. Asthma treatment in schoolchildren: lung function in different therapeutic groups. Acta Paediatr 1996; 85: 190-194.

9. Cockroft DW, Jokic R, Marciniuk DD, Fitzpatrick MF. The current dilemma with spirometric inclusion criteria for asthma drug trials. Ann Allergy Asthma Immunol 1997; 79: 226-228.

10. Birnie DW, thoe Schwartzenberg GWS, Hop WCJ, van Essen-Zandvliet EEM, Kerrebijn KF. Does the outcome of the tidal breathing dosimeter methods of assessing bronchial responsiveness in children with asthma depend on age? Thorax 1990; 45: 199-202.

11. Duiverman EJ, Neijens HJ, van Strik K, Affourtit MJ, Kerrebijn KF. Lung function and bronchial responsiveness in children who had infantile bronchiolitis. Pediatr Pulmonol 1987; 3: 38-44.
12. Pattemore PK, Asher MI, Harrison AC, Mitchell EA, Rea HH, Stewart AW. The interrelationship among bronchial hyperresponsiveness, the diagnosis of asthma, and asthma symptoms. Am Rev Respir Dis 1990; 142: $549-554$.

13. Sears MR, Jones DT, Holdaway MD, et al. Prevalence of bronchial reactivity to inhaled methacholine in New Zealand children. Thorax 1986; 41: $283-289$.

14. Gautrin D, Lapierre J-G, Malo J-L, Infante-Rivard C. Airway hyperresponsiveness and symptoms of asthma in a six-year follow-up study of childhood asthma. Chest 1999; 116: 1659-1664.

15. Martinez FD, Wright AL, Taussig LM, Holberg CJ, Halonen M, Morgan WJ, and the Group Health Medical Associates. Asthma and wheezing in the first six years of life. $N$ Engl J Med 1995; 332: $133-138$.

16. Stein RT, Holberg CJ, Morgan WJ, et al. Peak flow variability, methacholine responsiveness and atopy as markers for detecting different wheezing phenotypes in childhood. Thorax 1997; 52: 946-952.

17. Gruber W, Eber E, Steinbrugger B, Modl M, Weinhandl E, Zach MS. Atopy, lung function, and bronchial responsiveness in symptom-free paediatric asthma patients. Eur Respir J 1997; 10: 1041-1045.

18. Wilson NM, Dore CJ, Silverman M. Factors relating to the severity of symptoms at 5 years in children with severe wheeze in the first 2 years of life. Eur Respir $J$ 1997; 10: 346-353.

19. In't Veen JCCM, Smits HH, Hiemstra PS, Zwinderman AE, Sterk PJ, Bel EH. Lung function and sputum characteristics of patients with severe asthma during an induced exacerbation by double blind steroid withdrawal. Am J Respir Crit Care Med 1999; 160: 93-99.

20. Waalkens HJ, van Essen-Zandvliet EEM, Hughes $\mathrm{MD}$, et al. Cessation of long-term treatment with inhaled corticosteroid (budesonide) in children with asthma results in deterioration. Am Rev Respir Dis 1993; 148: $1252-1257$.

21. Pedersen S. Why does airway inflammation persist? Is it failure to treat early? Am J Respir Crit Care Med 2000; 161: S182-S185.

22. Kraft M, Martin RJ, Wilson S, Djukanovic R, Holgate ST. Lymphocyte and eosinophil influx into alveolar tissue in nocturnal asthma. Am J Respir Crit Care Med 1999; 159: 228-234.

23. van der Heide S, De Monchy JG, De Vries K, Dubois AE, Kauffman HF. Seasonal differences in airway hyperresponsiveness in asthmatic patients: relationship with allergen exposure and sensitization to house dust mites. Clin Exp Allergy 1997; 27: 627-633.

24. Avital A, Springer C, Bar-Yishay E, Godfret S. Adenosine, methacholine, and exercise challenges in children with asthma or paediatric chronic obstructive pulmonary disease. Thorax 1995; 50: 511-516.

25. Riedler J. Nonpharmacological challenges in the assessment of bronchial responsiveness. Eur Respir Mon 1997; 5: 115-135. 